\title{
ANTIBACTERIAL ACTIVITY OF SILVER NANOPARTICLES OBTAINED BY CO-REDUCTION WITH SODIUM CITRATE AND TANNIC ACID
}

\author{
SORIN RAPUNTEAN ${ }^{\mathrm{a}}$, REKA BALINT ${ }^{\mathrm{b}}$, GERTRUD ALEXANDRA \\ PALTINEAN $^{b}$, GHEORGHE TOMOAIA ${ }^{c, d}$, AURORA MOCANU ${ }^{b, *}$, \\ CSABA-PAL RACZ ${ }^{b}$, OSSI HOROVITZ ${ }^{b}$, MARIA TOMOAIA-COTISEL ${ }^{b, d}$
}

\begin{abstract}
The wet chemical synthesis of silver nanoparticles (AgNPs) by reduction of silver nitrate with sodium citrate, tannic acid, and their mixture is reported. The obtained silver nanoparticles were investigated by UV-Vis spectroscopy, scanning transmission electron microscopy (STEM), and atomic force microscopy (AFM) images and their antibacterial effect against Escherichia coli was assessed.
\end{abstract}

Keywords: silver nanoparticles, sodium citrate, tannic acid, UV-Vis spectra, STEM, AFM, antibacterial effect

\section{INTRODUCTION}

In the present war against antibiotic resistant bacterial strains, the old remedies with antimicrobial properties, such as certain metals or metal oxides were revived, but in the modern formula of nanoparticles (NPs). Most research is consecrated to silver nanoparticles (AgNPs), single or in association with antibiotics [1-12]. Nevertheless, the mechanism of the antibacterial action of

\footnotetext{
a University of Agricultural Sciences and Veterinary Medicine of Cluj-Napoca, 3-5, Manastur Str., RO-400372, Cluj-Napoca, Romania

b Babes-Bolyai University of Cluj-Napoca, Faculty of Chemistry and Chemical Engineering, Physical Chemistry Centre, 11 Arany J. Str., RO-400028 Cluj-Napoca, Romania

c Iuliu Hatieganu University of Medicine and Pharmacy, Orthopedy and Traumatology Department, 47 Mosoiu T. Str., RO-400132 Cluj-Napoca, Romania

d Academy of Romanian Scientists, 54 Splaiul Independentei, RO-050094, Bucharest, Romania

* Corresponding author mocanu.aurora@gmail.com
} 
AgNPs is still not fully understood; is it due to the attack of AgNPs themselves on bacterial cells, or to the silver ions released by the nanoparticles, or to the production of reactive oxidative species [12-15], induced by AgNPs.

For the preparation of AgNPs, three categories of methods are mentioned in literature [14, 16-18]: chemical methods based on the reduction of $\mathrm{Ag}^{+}$ions in aqueous or in organic solution, physico-chemical methods (photo-physical and electrochemical) and biosynthesis. For the chemical methods in aqueous solution, various reduction agents were proposed, such as sodium citrate, sodium borohydride, hydrazine, glucose, hydroquinone, gallic acid, $\beta$-cyclodextrin, ascorbic acid, various plant extracts [7, 14-22]. Although, the excess of reduction agents acts sometimes also as stabilizer of the colloidal system of AgNPs, frequently supplementary capping agents are introduced, such as starch, gelatin, polyvinylpyrrolidone (PVP), polyvinyl alcohol (PVA), poly-L-lysine, cetyltrimethyl-ammonium bromide (CTAB) and other surfactants $[18,23]$.

Tannic acid (TA, $\left.\mathrm{C}_{76} \mathrm{H}_{52} \mathrm{O}_{46}\right)$ was also proposed, single or associated with another reduction agent, for the synthesis of metal nanoparticles [24], having many phenolic groups in the structure. Due to its large molecule (molar mass: $1700 \mathrm{~g}$ ), TA appears itself as nanoparticle (hydrodynamic diameter 1.63 $\mathrm{nm}$ ) [25]. It becomes unstable when temperature and $\mathrm{pH}$ increase, and suffers hydrolysis and oxidation reactions. The AgNPs modified with TA were proposed as microbicides and for wound healing [26-28]. TA was used for the preparation of AgNPs [22, 24, 29-34]. TA was also used together with sodium citrate to prepare AgNPs [35, 36] mainly for catalytic properties [35].

Our study is the first investigation to compare the synthesis of AgNPs using trisodium citrate (TSC) and TA independently and together at various molar ratios for the reduction of $\mathrm{Ag}^{+}$ions in $\mathrm{AgNO}_{3}$ aqueous solutions to obtain AgNPs. Further, the characteristics of AgNPs realized by co-reduction for different mole ratios of the reagents and their biological effect on Escherichia coli were examined.

\section{RESULTS AND DISCUSSION}

The samples prepared (colloidal silver solutions) from the various syntheses are presented in Table 1, along with the compositions of the mixtures of reactants (molar concentration and weight percentage), and the silver content in the final solution. 
Table 1. The content of reactants in the syntheses of AgNPs and silver amount in the final colloidal solution

\begin{tabular}{|c|c|c|c|c|c|c|c|}
\hline \multirow[t]{2}{*}{ Sample Code } & \multicolumn{3}{|c|}{ Content (mM/L) } & \multicolumn{3}{|c|}{ Content (wt \%) } & \multirow{2}{*}{$\begin{array}{c}\mathrm{Ag} \\
(\mathrm{mg} / \mathrm{L})\end{array}$} \\
\hline & $\mathrm{AgNO}_{3}$ & TSC & TA & $\mathrm{AgNO}_{3}$ & TSC & TA & \\
\hline Ag-TSC & 0.96 & 1.49 & - & 0.0163 & 0.0384 & - & 104 \\
\hline Ag-TA & & - & 2 & 0.017 & - & 0.34 & 108 \\
\hline Ag-TSC-TA 1:7:2 & 1 & 7 & 2 & 0.017 & 0.1806 & 0.34 & 108 \\
\hline Ag-TSC-TA 1:7:0.2 & 0.25 & 1.75 & 0.05 & 0.00425 & 0.0452 & 0.0085 & 27 \\
\hline Ag-TSC-TA 1:3:0.2 & 0.25 & 0.75 & 0.05 & 0.00425 & 0.0193 & 0.0085 & 27 \\
\hline Ag-TSC-TA 1:20:0.1 & 0.25 & 5 & 0.025 & 0.00425 & 0.129 & 0.00425 & 27 \\
\hline
\end{tabular}

UV-Vis spectra. Trisodium citrate and silver nitrate solutions present no absorption bands in the visible range of spectra. The light yellow colored tannic acid solutions $(\mathrm{pH} 6)$ present at higher TA concentrations a large absorption band in UV and at the lowest wavelengths in the visible spectrum. A shoulder is seen at about $370-380 \mathrm{~nm}$. In diluted solution a deconvolution occurs, and two distinct bands are observed in the UV domain at 210 and 280 $\mathrm{nm}$ (Fig. 1a), in agreement with related data [22]. At higher pH values (alkaline medium, $\mathrm{pH}$ about 9 ), obtained by addition of potassium carbonate, the color turns rapidly to brown, due to the oxidation of phenolic groups by absorbed oxygen. The process is intensified by boiling (Fig. $1 \mathrm{~b}$ ).

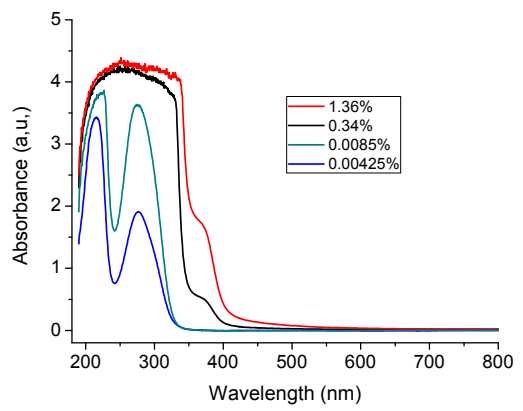

a

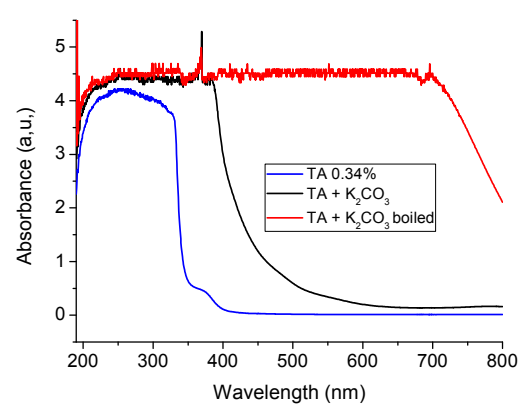

b

Figure 1. UV-Vis spectra: (a) aqueous solutions with different tannic acid content; (b) $0.34 \%(2 \mathrm{mM})$ tannic acid solution at $\mathrm{pH} 6$, after alkalization with $\mathrm{K}_{2} \mathrm{CO}_{3}(1 \mathrm{~g} / 100 \mathrm{~mL})$, and after boiling the alkaline solution for $15 \mathrm{~min}$.

The UV-Vis spectra of the AgNPs obtained by reduction with TSC were measured in time (Fig. 2a) and the changes are minor for 10 days. The maximum absorption of the silver surface plasmon resonance (SPR) band is at $415-417 \mathrm{~nm}$. 


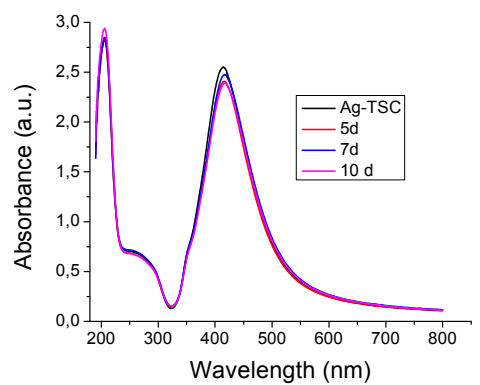

a

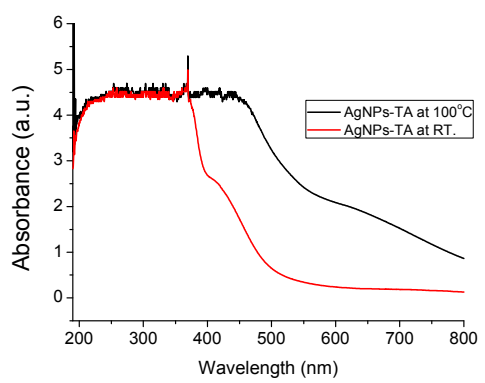

b

Figure 2. UV-Vis spectra of AgNPs obtained by reduction with TSC (a) and by reduction with TA at room temperature (RT) and at $100^{\circ} \mathrm{C}(\mathrm{b})$.

The solution obtained by reduction with TA ( $\mathrm{Ag} 1 \mathrm{mM}$, TA $2 \mathrm{mM}$, as given in Table 1) at room temperature and at boiling temperature was diluted 8 fold with ultrapure water for the UV-Vis measurement (Fig. 2b). The characteristic SPR band of AgNPs cannot be distinguished because of its overlapping with the absorption band of TA and its oxidation products (resulted from the reaction with silver nitrate), the last one being more extended at higher temperature, as observed also for pure TA solutions (Fig. 1b).

The AgNPs dispersion obtained by reduction with TSC and TA in the mole ratios Ag:TSC:TA for 1:7:2 (Table 1), with concentrations: Ag $1 \mathrm{mM}$, TSC $7 \mathrm{mM}$, tannic acid $2 \mathrm{mM}(0.34 \%)$ had to be 4 fold diluted before measuring the UV-Vis spectra, in order to distinguish between the absorption bands for TA and the SPR band of AgNPs (Fig. 3a). The spectrum is rather unmodified for 5 days. The characteristic SPR band of AgNPs presents the maximum at 418 $\mathrm{nm}$, while another lower peak is visible at $428 \mathrm{~nm}$.

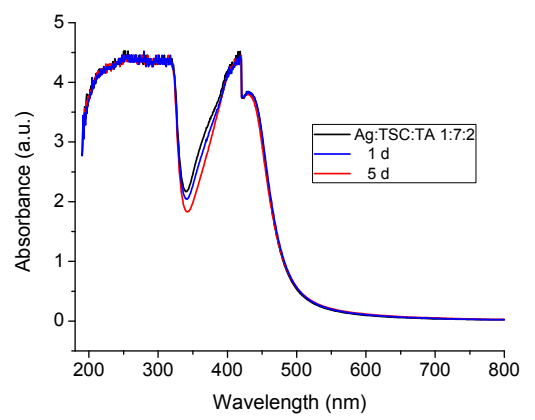

a

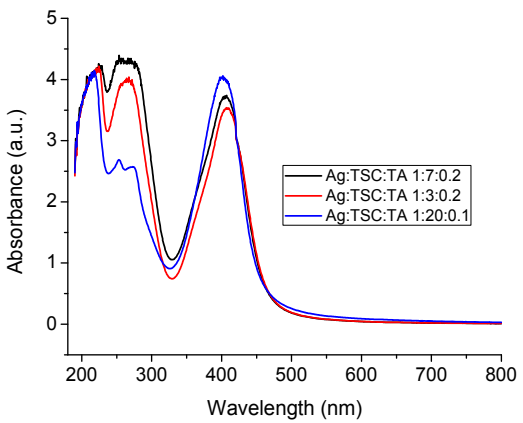

b

Figure 3. UV-Vis spectra of AgNPs prepared from $\mathrm{AgNO}_{3}$ with trisodium citrate and tannic acid in molar ratio Ag:TSC:TA of 1:7:2, time evolution (a); comparison of UV-Vis spectra of AgNPs (b), prepared with different mole ratios of the reagents: Ag:TSC:TA, 1:7:0.2; 1:3:0.2; 1:20:0.1 (as given in Table 1); the Ag concentration in the final solutions was $0.25 \mathrm{mM}$. 
The spectra for the molar ratios Ag:TSC:TA 1:7:0.2 and 1:3:0.2, and 1:20:0.1 are compared in Fig. 3b. With a lowering of the TA content, the absorption band of TA and the SPR band of AgNPs become clearly separated; the maxima for AgNPs appear at $407 \mathrm{~nm}$ (1:7:0.2), $408 \mathrm{~nm}$ (1:3:0.2), and $402 \mathrm{~nm}$ (1:20:0.1). The UV absorption band of TA in UV is split in two, as in Fig. 1a for low TA concentrations. In time, the AgNPs absorption bands remain almost unchanged for all samples (e.g. Fig. 3a).

STEM images. In the STEM images: Fig. 4a,b for AgNPs prepared with the Ag:TSC:TA 1:7:2 mole ratio, and Fig. 4c, d for those with 1:20:0.1 mole ratio, nearly spherical shaped AgNPs are observed. The sizes of the AgNPs in the samples were evaluated by measuring the diameters of a large number of particles on micrographs. For the different samples, the average diameter of particles was evaluated \pm the standard deviation going from $10 \pm 5 \mathrm{~nm}$ (Ag:TSC:TA for 1:20:0.1) to $31 \pm 7 \mathrm{~nm}$ (Ag:TSC:TA for 1:7:2).

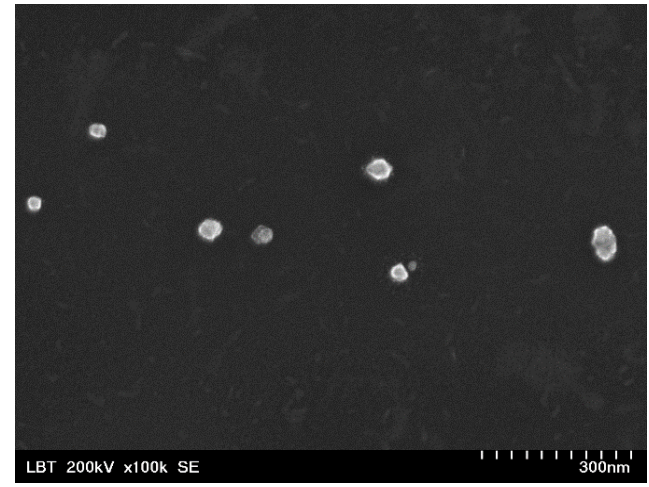

a

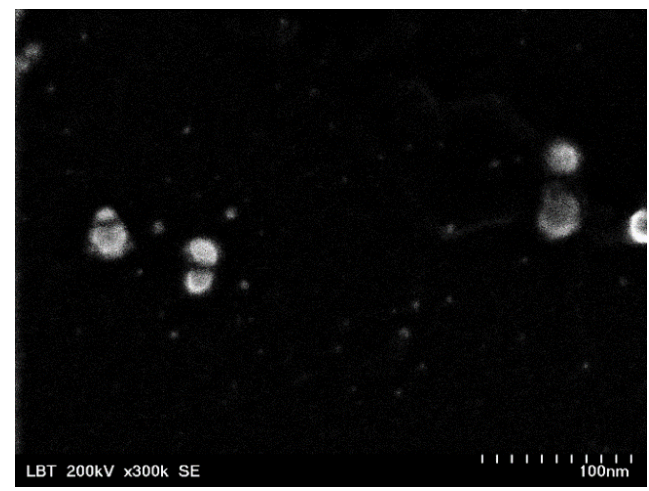

$\mathrm{C}$

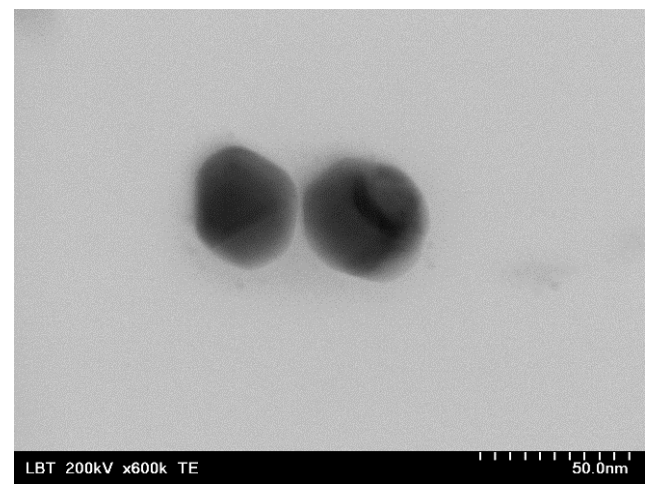

b

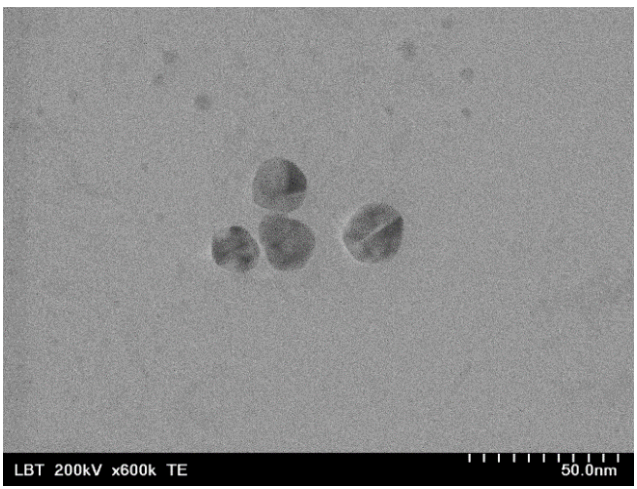

d

Figure 4. SE (a, c) and TE (b, d) images for AgNPs obtained with Ag:TSC:TA mole ratios 1:7:2 (a, b), and 1:20:0.1 (c, d). The scales in the STEM images correspond to $300 \mathrm{~nm}(\mathrm{a}), 100 \mathrm{~nm}$ (c), and $50 \mathrm{~nm}$ (b, d). 
In the energy dispersive X-ray spectroscopy, EDX spectra of AgNPs, obtained on STEM images (as in the example presented in Fig. 5a,b), the presence of $\mathrm{Ag}$, as well of the elements from the organic compounds is evidenced (Fig. 5b). In Fig. 5c-f, the corresponding multicolor distribution maps for the individual elements $(\mathrm{C}, \mathrm{N}, \mathrm{O}$ and $\mathrm{Ag})$ can be seen. The distribution maps confirm the presence of $\mathrm{Ag}$ mainly within the nanoparticle, while the other elements are distributed over the entire scanned area, due to the presence of the organic compounds (TSC, TA and their oxidation products) around the particles and among them, being adsorbed on STEM grid from deposited colloidal solution.

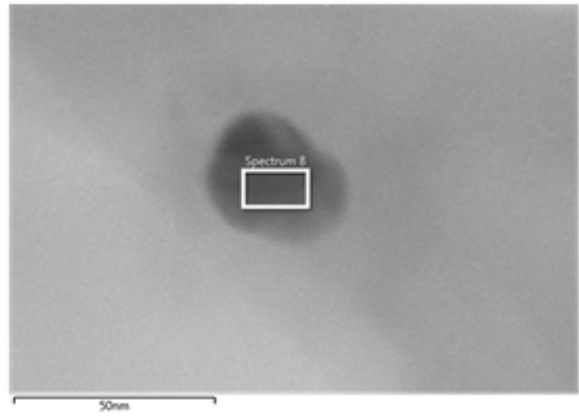

a

C K series

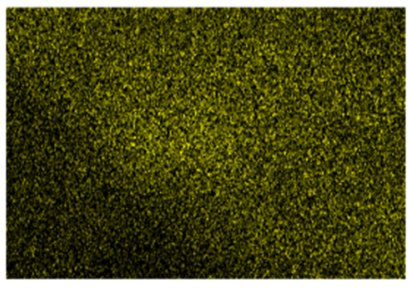

$50 \mathrm{~nm}$

$50 \mathrm{~nm}$

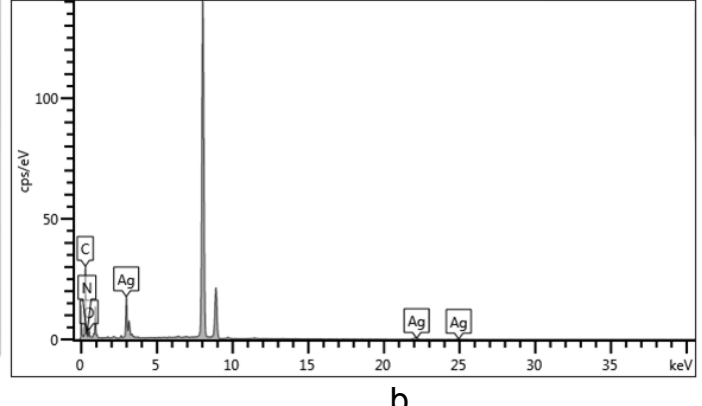

N K series

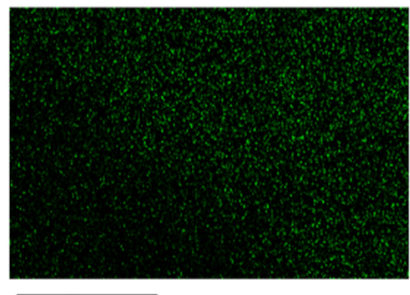

d

Ag K series

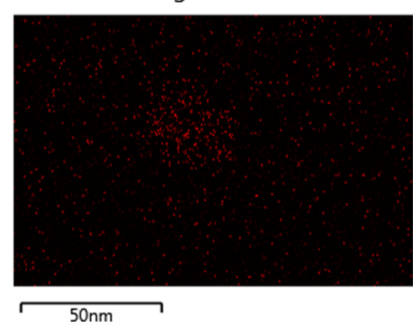

$f$

Figure 5. Electron image (a) and EDX spectrum (b), on AgNPs (within the white frame, shown in panel a) obtained for the Ag:TSC:TA sample at 1:3:0.2 mole ratio; distribution maps for $\mathrm{C}(\mathrm{c}), \mathrm{N}(\mathrm{d}), \mathrm{O}(\mathrm{e})$ and $\mathrm{Ag}(\mathrm{f})$; bars in the images are of $50 \mathrm{~nm}$. 
As a representative example, Fig. 6 presents AFM images on AgNPs obtained with the Ag:TSC:TA sample, having the 1:20:0.1 mole ratio. On AFM images, shape and size of nanoparticles can be estimated. The diameters of AgNPs, assessed from these images, are consistent with size obtained from STEM images, namely $30 \mathrm{~nm} \pm 5 \mathrm{~nm}$ for Ag:TSC:TA at 1:7:2 molar ratio; $22 \pm$ $4 \mathrm{~nm}$ for Ag:TSC:TA at 1:3:0.2; $16 \mathrm{~nm} \pm 4 \mathrm{~nm}$ for Ag:TSC:TA at 1:7:0.2; and $10 \pm 3 \mathrm{~nm}$ for Ag:TSC:TA at 1:20:01.

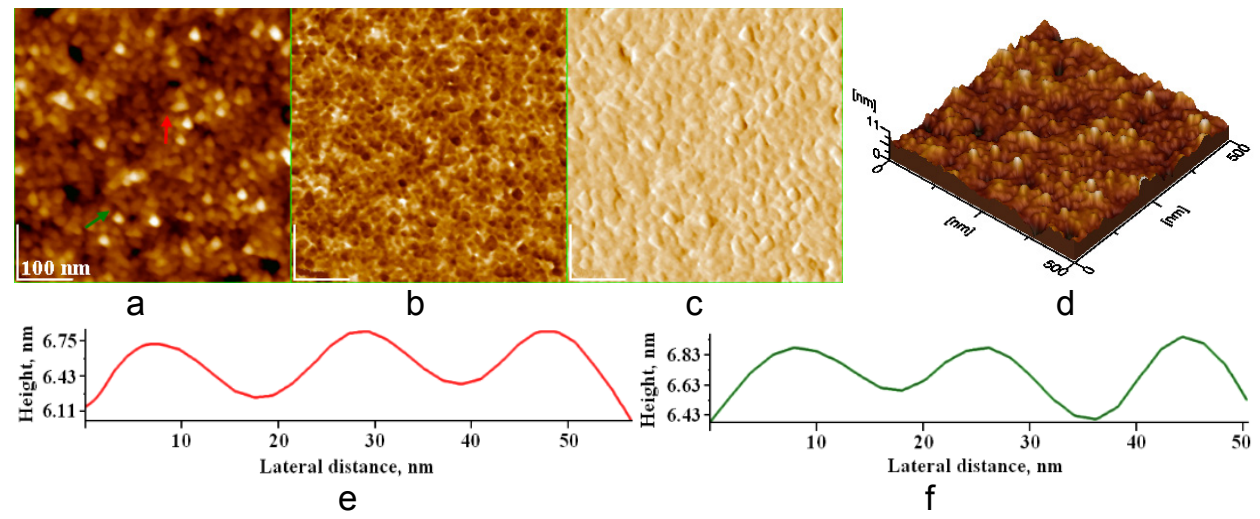

Figure 6. AFM images: 2D-topography (a), phase (b), amplitude (c) and 3Dtopography (d) of AgNPs from Ag-TSC-TA sample at 1:20:0.1 mole ratio, deposited on glass by adsorption for $10 \mathrm{~s}$; scanned area $500 \mathrm{~nm} \times 500 \mathrm{~nm}$; (e, f) cross section profiles along the arrows in panel a. Particles size is $10 \mathrm{~nm} \pm 3 \mathrm{~nm}$.

Antimicrobial activity. Figure 7a shows the agar plate with bacterial colonies of Escherichia coli 25922 ATCC after incubation at $37^{\circ} \mathrm{C}$ for 24 hours. The wells contained equal amounts $(20 \mu \mathrm{L})$ of the solutions to be tested. Among the four colloidal solutions, containing AgNPs with different Ag:TSC:TA mole ratios (Table 1), the largest inhibition zone were observed for the samples 1 and 2, corresponding to the mole ratios Ag:TSC:TA of 1:7:2 and 1:20:0.1 (Fig. 7b), respectively. The sample 2 had a lower silver content of $0.25 \mathrm{mM} \mathrm{Ag}$ in comparison with $1 \mathrm{mM} \mathrm{Ag}$ in the first sample, (Table 1), but showed a rather high antibacterial effect (Fig. 7b). This high antibacterial effect can be assigned to its smallest AgNPs (about $10 \mathrm{~nm}$ in average diameter).

The inhibition zone for the sample 3 , corresponding to $\mathrm{Ag}(0.25 \mathrm{mM})$ TSC-TA at 1:7:0.2 mole ratio is lower than for its value for samples 1 and 2 . The lowest value of inhibition zone is for sample 4, corresponding to the $\mathrm{Ag}(0.25 \mathrm{mM})-\mathrm{TSC}-\mathrm{TA}$ at 1:3:0.2 mole ratio. For the last two samples, the size of particles is somehow bigger than the size of sample 2, but still smaller than the size of sample 1. Thus, antimicrobial activity of these samples appears to be related primarily with the average size of the AgNPs. 
The inhibition zone for the $1 \mathrm{mM} \mathrm{AgNO}$ solution is also important (sample 6), while the TSC solution (sample 5) and pure water (negative control, NC sample) presented no inhibition zones.

In addition, these results demonstrated that to increase the antibacterial activity of AgNPs, various reaction parameters should be considered, among which the mole ratio of reducing agent (TSC) and stabilizing (capping, TA) agent of NPs seems to be a crucial factor, to finally produce stable NPs of various sizes, and preferably small average diameters. These results are also consistent with our previous results, in which the antimicrobial activity of AgNPs was dependent on the silver amount [7] and on the size of nanoparticles.

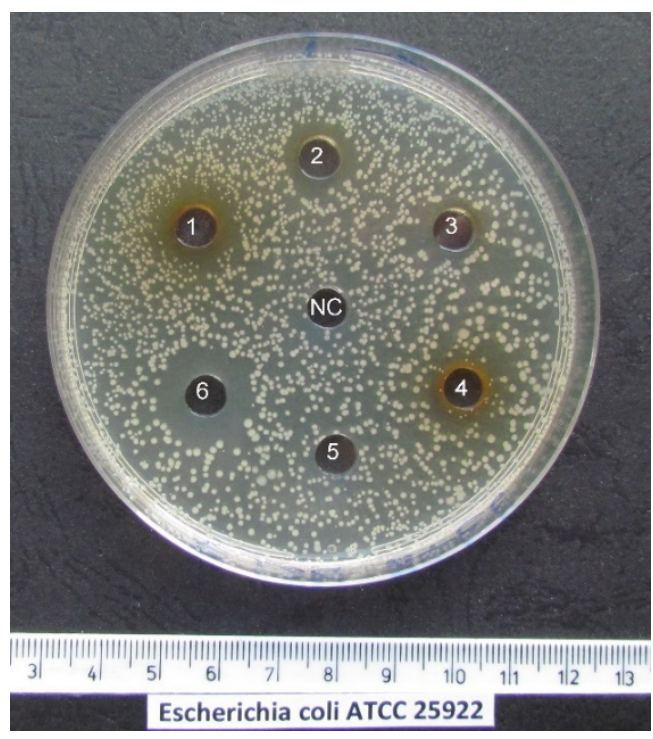

a

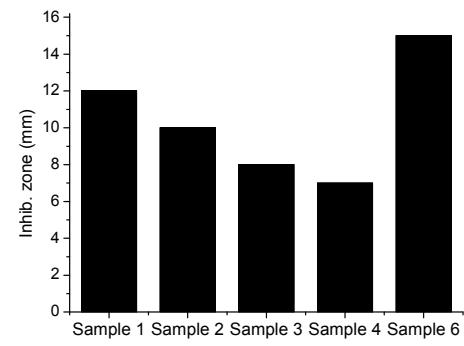

b

Figure 7. (a) Inhibition zones for Escherichia coli 25922 ATCC in presence of AgNPs dispersions $(20 \mu \mathrm{L})$. Samples are numbered as follows: (1) - $\mathrm{Ag}(1 \mathrm{mM})-$ TSC-TA for 1:7:2 mole ratio; (2) - Ag (0.25 mM)-TSC-TA for 1:20:0.1; (3) - Ag (0.25 mM)-TSC-TA for 1:7:0.2 mole ratio; (4) - Ag (0.25 mM)-TSC-TA for 1:3:0.2 mole ratio; (5)- TSC (7 mM); (6) - $\mathrm{AgNO}_{3}(1 \mathrm{mM}) ; \mathrm{NC}$ (negative control), pure water sample; (b) Comparison between inhibition zones for different samples.

Our results confirm the higher antibacterial activity of smaller particles, as previously observed by in other investigations, for instance [12, 37]. This effect can be explained by the theory which assigns the antibacterial effect to the AgNPs themselves [38], since smaller particles have a larger specific surface area, being able to stronger interact with the cell membrane [14], or 
maybe penetrate into the cell [1]. On the other hand, if the antibacterial effect were due to the $\mathrm{Ag}^{+}$ions [13,39], it is again the higher specific surface area which would guarantee a higher release of silver ions. To these reasoning we could add that for the diffusion in agar plates, which is slower than in liquid medium, smaller particles have a higher mobility, thus increasing the size of inhibition zones.

\section{CONCLUSIONS}

The co-reduction of silver nitrate in aqueous solution with TSC and TA proved to be a simple and rapid one-pot method to prepare AgNPs, with controlled size, from 30 to $10 \mathrm{~nm}$, as shown by STEM and AFM images. The presence of elementary silver is evident form the UV-Vis spectra (characteristic SPR band) and from the EDX spectra and elements distribution maps. The antibacterial effect of the AgNPs was tested by measuring the inhibition zones on cultures of Escherichia coli. The effect was evident for all AgNPs samples, but the AgNPs with smallest size proved to be the most active. Thus AgNPs obtained by the investigated methods could be successfully used, as such or in association with antibiotics, against bacterial infections.

\section{EXPERIMENTAL SECTION}

\section{Synthesis of silver nanoparticles (AgNPs)}

The reduction of silver nitrate with sodium citrate $[40,41]$ was achieved by boiling for $30 \mathrm{~min}$, under continuous stirring, a mixture of $5 \mathrm{~mL} 1 \%$ trisodium citrate, TSC $\left(\mathrm{Na}_{3} \mathrm{C}_{6} \mathrm{H}_{5} \mathrm{O}_{7}\right.$, high purity, above $99 \%$, from Sigma Aldrich) aqueous solution with $125 \mathrm{~mL} 1 \mathrm{mM} \mathrm{AgNO}_{3}$ (from Merck, high purity above 99.5\%). The mole ratio TSC/Ag was 1.55. The pale yellow solution obtained was cooled on an ice-water mixture at room temperature. The colloidal solution (Ag content $104 \mathrm{mg} / \mathrm{L}, 0.96 \mathrm{mM}$ ) kept in brown bottles at $4^{\circ} \mathrm{C}$, was stable for at least 2 months

Tannic acid (TA) was also tested as reducing agent for $\mathrm{AgNO}_{3}$. The $10^{-2} \mathrm{M} \mathrm{AgNO}_{3}$ solution $(10 \mathrm{~mL}$ ) with $80 \mathrm{~mL}$ water was mixed with $10 \mathrm{~mL} 3.4 \%$ tannic acid (from Merck) solution $\left(2 \cdot 10^{-2} \mathrm{M}\right)$ (molar ratio $\left.\mathrm{Ag} / \mathrm{TA}=1: 2\right)$ at room temperature and at boiling temperature. The yellow color due to the TA solution was intensified during the reaction, and shifted to brown, more intensely at high temperature. The resulting colloid solution had a silver content of $108 \mathrm{mg} / \mathrm{L}(1 \mathrm{mM})$. 
The co-reduction of silver nitrate with sodium citrate and tannic acid for variable $\mathrm{Ag} / \mathrm{TSC} / \mathrm{TA}$ mole ratios (Table 1 ) was performed $[35,36]$, by heating up the $\mathrm{AgNO}_{3}$ solution to boiling, and then adding the calculated amount of TSC and TA mixture. The solutions were kept boiling, under continuous stirring, for $15 \mathrm{~min}$. The colloidal silver obtained by complete reduction of $\mathrm{Ag}^{+}$ to $\mathrm{Ag}$ was $1 \mathrm{mM}$ in the $\mathrm{Ag}$-TSC-TA for $1: 7: 2$ mole ratio, and $0.25 \mathrm{mM}$ for 1:7:0.2, 1:3:0.2 and 1:20:0.1 mole ratios.

\section{Measurements and instrumentation}

For UV-VIS absorption spectra measurements the Jasco UV/Vis V650 spectrophotometer was used, in the domain from 800 to $190 \mathrm{~nm}$ wavelength. Too intense colored solutions (containing TA or its oxidation products) had to be diluted with water before measurements.

STEM is a combined scanning electron (SE) and scanning transmission electron (TE ) microscope, Hitachi HD-2700, operating at a maximum accelerating voltage of $200 \mathrm{kV}$. STEM is equipped with energy-dispersive X-ray spectrometer (EDS), which has two EDX detectors, from Oxford Instruments. STEM-EDS equipment was also used for EDX elemental analysis.

Layers of AgNPs on glass support were prepared by vertical adsorption from the colloidal solutions for $10 \mathrm{~s}$ and dried in air. They were investigated by atomic force microscopy, AFM JEOL 4210 equipment, operated in tapping mode [42-48] using standard cantilevers with silicon nitride tips (resonant frequency in the range of $200-300 \mathrm{kHz}$ and spring constant $17.5 \mathrm{~N} / \mathrm{m}$ ). On each film, areas from $10 \mu \mathrm{m} \times 10 \mu \mathrm{m}$ up to $0.05 \mu \mathrm{m} \times 0.05 \mu \mathrm{m}$ were scanned, and 2D- and 3D- topographies, phase and amplitude images and cross sections profiles in the adsorbed AgNPs layer were processed by the standard AFM procedures

Antibacterial assays. The bacterial strain tested was Escherichia coli ATCC 25922 (Gram negative bacteria), cultivated on glucose nutrient agar (Merck KGaA, Germany); suspensions in nutrient broth were prepared corresponding to a turbidity of 0.5 on the McFarland standards $\left(1.5 \times 10^{8}\right.$ $\mathrm{CFU} / \mathrm{mL})$.

The Kirby-Bauer technique [7] (disk diffusion assay) in nutrient agar with glucose, was applied to evaluate the antimicrobial effect of the AgNPs solutions. On nutrient agar plates ( $3 \mathrm{~mm}$ thick, diameter $90 \mathrm{~mm}$ ), the bacterial suspension was introduced and uniformly dispersed. After drying the agar surface, on each plate 6 wells (diameter $6 \mathrm{~mm}$ ) in radial disposition and a central one were cut and in each $20 \mu \mathrm{L}$ liquid samples were introduced, namely the four AgNPs dispersions obtained by reduction with TSC and TA (Table 1), TSC solution, $1 \mathrm{mM} \mathrm{AgNO}_{3}$ solution, and pure water as negative control in the 
central well. The plates were incubated for $24 \mathrm{~h}$ at $37^{\circ} \mathrm{C}$, and after that the diameters of the inhibition zones formed around the samples were measured and photographed. The plates were kept under surveillance for another $72 \mathrm{~h}$, in order to reveal possible changes in time. The antimicrobial effect of AgNPs was sustained on Escherichia coli ATCC 25922.

\section{ACKNOWLEDGMENTS}

Authors acknowledge the financial support from Executive Unit for Financing Higher Education, Research, Development and Innovation (UEFISCDI) through the project number 83 .

\section{REFERE NCES}

1. J.R. Morones, J.L. Elechiguerra, A. Camacho, K. Holt, J.B. Kouri, J.T. Ramırez, M. J. Yacaman, Nanotechnology, 2005, 16(10), 2346.

2. M. Rai, A. Yadav, A. Gade, Biotechnology Advances, 2009, 27(1), 76.

3. M.K. Rai, S.D. Deshmukh, A.P. Ingle, A.K. Gade, Journal of Applied. Microbiology, 2012, 112(5), 841.

4. M.J. Hajipour, K.M. Fromm, A.A. Ashkarran, D.J. de Aberasturi, I.R. de Larramendi, T. Rojo, V. Serpooshan, W.J. Parak, M. Mahmoudi, Trends in Biotechnology, 2012, 30(10), 499.

5. S. Chernousova, M. Epple, Angewandte Chemie International Edition, 2013, 52(6), 1636.

6. A. Ravindran, P. Chandran, S. Sudheer Khan, Colloids and Surfaces B: Biointerfaces, 2013, 105, 342.

7. A. Mocanu, G. Furtos, S. Rapuntean, O. Horovitz, C. Flore, C. Garbo, A. Danisteanu, G. Rapuntean, C. Prejmerean, M. Tomoaia-Cotisel, Applied Surface Science, 2014, 298, 225.

8. G. Franci, A. Falanga, S. Galdiero, L. Palomba, M. Rai, G. Morelli, M. Galdiero, Molecules, 2015, 20(5), 8856.

9. B. Le Ouay, F. Stellacci, Nano Today, 2015, 10(3), 339.

10. N. Durán, G. Nakazato, A.B. Seabra, Applied Microbiology and Biotechnology, 2016, 100(15), 6555.

11. J.S. Möhler, W. Sim, M.A.T. Blaskovich, M.A. Cooper, Z.M. Ziora, Biotechnology Advances, 2018, 36(5), 1391.

12. V. Pareek, R. Gupta, J. Panwar, Materials Science \& Engineering C, 2018, 90, 739. 
S. RAPUNTEAN, R. BALINT, G.A. PALTINEAN, G. TOMOAIA, A. MOCANU, CS.-P RACZ, O. HOROVITZ, M. TOMOAIA-COTISEL

13. R. Ma, C. Levard, S.M. Marinakos, Y. Cheng, J. Liu, F.M. Michel, G.E. Brown Jr, G.V. Lowry, Environmental Science \& Technology, 2012, 46(2), 752.

14. J.J. Naddeo, M. Ratti, S.M. O'Malley, J.C. Griepenburg, D.M. Bubb, E.A. Klein, Advanced Science, Engineering and Medicine, 2015, 7(12), 1044.

15. U.T Khatoon, G.V.S. Nageswara Rao, K.M. Mohan, A. Ramanaviciene, A. Ramanavicius, Vacuum, 2017, 146, 259.

16. N.L. Pacioni, C.D. Borsarelli, V. Rey, A.V. Veglia, In „Silver Nanoparticle Applications in the Fabrication and Design of Medical and Biosensing Devices", Springer, Switzerland, 2015, pp. 13-46.

17. K.S. Siddiqi, A. Husen, R.A.K. Rao, Journal of Nanobiotechnology, 2018, 16:14. https://doi.org/10.1186/s12951-018-0334-5

18. V. Chahar, B. Sharma, G. Shukla, A. Srivastava, A. Bhatnagar, Colloids and Surfaces A: Physicochemical and Engineering Aspects, 2018, 554, 149.

19. A. Mocanu, O. Horovitz, C.P. Racz, M. Tomoaia-Cotisel, Revue Roumaine de Chimie, 2015, 60(7-8), 721.

20. A.R. Shet, P. Ghose, L. Patil, V. Hombalimath, International Journal of Current Biotechnology, 2015, 3(2):1.

21. S. Aashritha, International Research Journal of Pharmacy, 2013, 4, 111.

22. Y. Hao, N. Zhang, J. Luo, X. Liu, NANO: Brief Reports and Reviews, 2018, 13 1850003, DOI: 10.1142/S1793292018500030.

23. A.L. Kubo, I. Capjak, I.V. Vrček, O.M. Bondarenko, I. Kurvet, H. Vija, A. Ivask, K. Kasemets, A. Kahru, Colloids and Surfaces B: Biointerfaces, 2018, 170, 401.

24. T. Ahmad, Journal of Nanotechnology, 2014, Article ID 954206, http://dx.doi.org/10.1155/2014/954206

25. M. Ocwieja, A. Popov, Z. Adamczyk, M. Morga, A. Ramanaviciene, A. Ramanavicius, Colloids and Surfaces A: Physicochemical and Engineering Aspects, 2015, 477, 70.

26. P. Orlowski, M. Krzyzowska, R. Zdanowski, A. Winnicka, J. Nowakowska, W. Stankiewicz, E. Tomaszewska, G. Celichowski, J. Grobelny, Toxicology in Vitro, 2013, 27(6), 1798.

27. P. Orlowski, K. Soliwoda, E. Tomaszewska, K. Bien, A. Fruba, M. Gniadek, O. Labedz, Z. Nowak, G. Celichowski, J. Grobelny, M. Krzyzowska, Toxicology in Vitro, 2016, 35, 43.

28. P. Orlowski, M. Zmigrodzka, E. Tomaszewska, K. Ranoszek-Soliwoda, M. Czupryn, M. Antos-Bielska, J. Szemraj, G. Celichowski, J. Grobelny, M. Krzyzowska, International Journal of Nanomedicine, 2018, 13, 991.

29. S.K. Sivaraman, I. Elango, S. Kumar, V. Santhanam, Current Science, 2009, 97(7), 1055.

30. U.K. Parashar, V. Kumar, T. Bera, P.S. Saxena, G. Nath, S.K. Srivastava, R. Giri, A. Srivastava, Nanotechnology, 2011, 22(41), 415104.

31. I. Călinescu, M. Pătraşcu, A.I. Gavrilă, A. Trifan, C. Boscornea, U.P.B. Scientific Bulletin, Series $B, 2011,73(4), 1$.

32. Y. Cao, R. Zheng, X Ji, H. Liu, R. Xie, W. Yang, Langmuir, 2014, 30(13), 3876.

33. K. Watcharaporn, M. Opaprakasit, V. Pimpan, Advanced Materials Research, 2014, 911, 110. 
34. T.Y. Kim, S.H. Cha, S. Cho, Y. Park, Archives of Pharmacal Research, 2016, 39, 465.

35. N.G. Bastus, F. Merkoci, J. Piella, V. Puntes, Chemistry of Materials, 2014, 26, 2836.

36. K. Ranoszek-Soliwoda, E. Tomaszewska, E. Socha, P. Krzyczmonik, A. Ignaczak, P. Orlowski, M. Krzyzowska, G. Celichowski, J. Grobelny, Journal of Nanoparticle Research, 2017, 19:273, DOI 10.1007/s11051-017-3973-9

37. M. Akter, M.T. Sikder, M.M. Rahman, A.K.M.A. Ullah, K.F.B. Hossain, S. Banik, T. Hosokawa, T. Saito, M. Kurasaki, Journal of Advanced Research, 2018, 9, 1.

38. S. Agnihotri, S. Mukherji, S. Mukherji, RSC Advances, 2014, 4, 3974.

39. Z. Xiu, Q. Zhang, H.L. Puppala, V.L. Colvin, P.J.J. Alvarez, Nano Letters, 2012, 12(8), 4271.

40. P.V. Kamat, M. Flumiani, G.V. Hartland, Journal of Physical Chemistry B, 1998, 102, 3123.

41. O. Horovitz, M. Tomoaia-Cotisel, C. Racz, G. Tomoaia, L.D. Bobos, A. Mocanu, Studia Universitatis Babes-Bolyai, Chemia, 2009, 54(3), 89.

42. M. Tomoaia-Cotisel, A. Tomoaia-Cotisel, T. Yupsanis, G. Tomoaia, I. Balea, A. Mocanu, C. Racz, Revue Roumaine de Chimie, 2006, 51(12), 1181.

43. G. Tomoaia, M. Tomoaia-Cotisel, A. Mocanu, O. Horovitz, L.D. Bobos, M. Crisan, I. Petean, Journal of Optoelectronics and Advanced Materials, 2008, 10(4), 961.

44. G. Tomoaia, P.T. Frangopol, O. Horovitz, L.D. Bobos, A. Mocanu, M. TomoaiaCotisel, Journal of Nanoscience and Nanotechnology, 2011, 11(9), 7762.

45. A. Mocanu, R.D. Pasca, G. Tomoaia, C. Garbo, P.T. Frangopol, O. Horovitz, M. Tomoaia-Cotisel, International Journal of Nanomedicine, 2013, 8, 3867.

46. U.V. Zdrenghea, G. Tomoaia, D.V Pop-Toader, A. Mocanu, O. Horovitz, M. Tomoaia-Cotisel, Combinatorial Chemistry \& High Throughput Screening, 2011, 14(4), 237.

47. R.D. Pasca, A. Mocanu, S.C. Cobzac, I. Petean, O. Horovitz, M. TomoaiaCotisel, Particulate Science and Technology, 2014, 32(2), 131.

48. I. Petean, G. Tomoaia, O. Horovitz, A. Mocanu, M. Tomoaia-Cotisel, Journal of Optoelectronics and Advanced Materials, 2008, 10(9), 2289. 